\title{
An Application of $\mathrm{CO}_{2}$ as a Refrigerant for Medium Temperature Heat Pumps
}

\author{
Viktoriia V. Karnaukh* \\ Tugan-Baranovsky Donetsk National University \\ of Economics and Trade \\ Donetsk
}

Received 24.07.2021, received in revised form 17.08.2021, accepted 21.09.2021

\begin{abstract}
This paper presents the energetic and exergetic analysis of a transcritical carbon dioxide based heat pump cycle for heating. Recycled water $\left(\mathrm{t}_{\mathrm{w}}=25 \ldots 40^{\circ} \mathrm{C}\right)$ of food production enterprises is taken into account as a source of low potential heat. The theoretical and real $\mathrm{CO}_{2}$ trans-critical cycles were analysed. Parameters, which characterize cycles from energy and exergy point of view were obtained. The exergy flow diagram (Grassmann diagram) shows that all the components except the internal heat exchanger contribute significantly to the irreversibilities of the system.
\end{abstract}

Keywords: $\mathrm{CO}^{2}$ heat pump; exergy, exergy balance, coefficient of performance, exergy losses (destruction).

Citation: Karnaukh V.V. An application of $\mathrm{CO}_{2}$ as a refrigerant for medium temperature heat pumps, J. Sib. Fed. Univ. Eng. \& Technol., 2021, 14(6), 703-713. DOI: 10.17516/1999-494X-0344

\section{О применении $\mathrm{CO}_{2}$ в качестве холодильного агента}

\section{для среднетемпературных тепловых насосов}

B. B. Карнаух

Донецкий национальный университет экономики и торговли имени Михаила Туган-Барановского

Донеик

\begin{abstract}
Аннотация. В работе представлены результаты энергетического и эксергетического анализа теплового насоса, работающего на диоксиде углерода. В качестве источника низкопотенциальной теплоты рассматривается оборотная вода предприятий пищевых производств $\left(\mathrm{tw}=25 \ldots 40{ }^{\circ} \mathrm{C}\right)$. Были проанализированы теоретический и реальный транскритические циклы на $\mathrm{CO}_{2}$. Был получен ряд параметров, характеризующих эти циклы с термодинамической и эксергетической
\end{abstract}

(C) Siberian Federal University. All rights reserved

This work is licensed under a Creative Commons Attribution-Non Commercial 4.0 International License (CC BY-NC 4.0).

* Corresponding author E-mail address: karnaukh.vita0629@gmail.com 
точек зрения. Эксергетическая диаграмма потоков (диаграмма Гроссмана) показала, что все элементы системы, кроме промежуточного внутреннего теплообменника, вносят существенный вклад в необратимость работы системы.

Ключевые слова: $\mathrm{CO}_{2}$ тепловой насос, эксергия, эксергетический баланс, коэффициент преобразования, эксергетические потери.

Цитирование: Карнаух, В.В. О применении $\mathrm{CO}_{2}$ в качестве холодильного агента для среднетемпературных тепловых насосов / В. В. Карнаух // Журн. Сиб. федер. ун-та. Техника и технологии, 2021, 14(6). С. 703-713. DOI: 10.17516/1999-494X-0344

\section{Introduction}

As the population grows, the pressure on water resources increases significantly. In many cases, the energy and water systems in a process are closely linked.

The production of food is characterized as a high water consumption industry.

There are several types of water-using operations [1]:

- heating: boiler, heat exchangers;

- process water: cooling and cooling towers;

- potable uses: in offices and canteens;

- washing: of equipment, bottles, floor and vehicles;

- rinsing: of equipment, bottles, food materials and final products;

- sanitation: general cleaning and toilet flushing;

- fire fighting; and

- transport medium.

In many food industry enterprises, waste heat flows take place that are not reused for their own needs. They are usually discharged into the sewer system or local cooling towers. This applies to factories that produce alcohol, beer, dairy products, bakery products, etc. With a steady rise in energy prices, all this ultimately leads to an increase in unit costs for the production of final products and services.

In the works devoted to increasing the level of greening of industrial enterprises among the primary directions in the field of increasing the level of greening the food and processing industry, the need is noted $« \ldots$ to improve the entire water management system of enterprises, to increase the volume of recycled and reused water, to reduce the consumption of fresh water, to reduce the volume of waste water, especially contaminated and dumped without cleaning, with a promising transition to closed cycles».

Replacement of cooling towers, spray basins with heat pumps allows, along with stable, yearround cooling of technological equipment, independent of weather conditions, to utilize heat discharges both for the company's own heat supply needs and for heat supply with commercial heat to third-party consumers.

In this article recycled water $\left(t_{\mathrm{w}}=25 \ldots 40^{\circ} \mathrm{C}\right)$ of food production enterprises is taken into account as a source of low potential heat for medium-temperature water-to-water vapor compression heat pump.

In this case, the choice of the «ideal» working fluid is the primary requirement for the heat pumps efficiency. Ongoing trend in cooling area is using natural refrigerants with low ODP and GWP.

Several theoretical and experimental studies have spurred further interest in carbon dioxide based systems in varied applications. Environment friendliness, low price, easy availability, with various 
common materials, compactness due to high operating pressures, excellent transport properties are cited as some of the reasons behind the revival of carbon dioxide as a refrigerant.

Past studies indicate that carbon dioxide based systems have great potential in two sectors in mobile air conditioning and in heat pumps for simultaneous cooling and heating.

A large number of experimental work of $\mathrm{CO}_{2}$ heat pumps operate with low heat sources and in this case the evaporating temperature varies from $-10^{\circ} \mathrm{C}$ to $10^{\circ} \mathrm{C}[2-3]$. It was mentioned that due to a lower critical temperature a $\mathrm{CO}_{2}$ heat pump is not suitable for high temperature heat sources and gas cooler exit temperature from 30 to $50{ }^{\circ} \mathrm{C}$ was recommended.

However, deeper analyses demonstrates several studies were the evaporating temperature varies between 15 and $20^{\circ} \mathrm{C}$, and the condensing temperature comes up to $70{ }^{\circ} \mathrm{C}$ [4].

The purpose of this work is to evaluate carbon dioxide as a working substance for mediumtemperature water-to-water vapor compression heat pumps.

The object of research is the systems of recycled water supply of food production enterprises.

\section{Energetic and exergetic analysis}

The studies depending on the energy and exergy analysis are essential for the efficient utilization of energy recourses for a variety of systems.

Therefore, a growing trend has been observed towards these analyses in the last two decades. The traditional methods of process analysis (energy analysis) are based on the First Law of Thermodynamics. This method is the failure to consider changes in energy quality during a process, since it does not consider the properties of the environment around the system and not characterises the irreversibility of the processes within the system. Thus, it makes traditional thermodynamic analysis methods quite unsatisfactory. To overcome this inadequacy, the concept of exergy has quickly become a key instrument in recent years.

Exergy (value of energy) is a relatively alternative technique defined as the maximum useful work obtainable from the system, when its state is brought to the standard atmospheric conditions or a dead state. In the ideal energy conversion process no exergy is lost, but in any real process exergy destruction (irreversibility) takes place and it constitutes the main difference between energy and exergy. Hence, the exergy analysis is a more rational measure of environmental and economic performance of process than the energy analysis [5].

The second law of thermodynamics derives the concept of exergy, a powerful tool for analyzing both the quantity and quality of energy use. It is defined as the maximum amount of work achievable when the flow of matter is transferred from its initial state to a dead state by processes during which the flow can only interact with the environment. The exergy balance is similar to the energy balance, but it has a fundamental difference in that, although the energy balance is a statement of the law of conservation of energy, the exergy can be considered as a statement of the law of energy degradation.

Obviously, the studies depending on the energy and exergy analysis are essential for the efficient utilization of energy recourses for a variety of systems.

Provided analysis takes into account all the losses appearing in the heat pump system, for calculating exergetic efficiency. The various parameters calculated are $\mathrm{COP}_{\mathrm{h} . \mathrm{p}}, \mathrm{COP}_{\mathrm{Lorenz}}$, exergetic efficiency, exergy destruction.

$$
-705-
$$


In this study, in order to calculate thermodynamic efficiency of the medium-temperature waterto-water vapor compression heat pump the following simplifying assumptions have been made:

- Steady state conditions are remaining in all the components;

- Pressure losses in the pipelines are neglected;

- Heat is not transferred to the system by other means, only from refrigerant in the condenser to the outside ambient hot air or room air to refrigerant in the evaporator;

- Kinetic and potential energy and exergy losses are not considered;

- The flow is assumed to be adiabatic through the pipes, the throttle valve and compressor (for theoretical cycle);

- The isentropic efficiency of compressor is $85 \%$. (Y.F.GAO) for theoretical cycles; the compressor mechanical efficiency and the compressor motor electrical efficiency are $85 \%$ and $90 \%$, respectively (for real cycle);

- Dead state of the refrigerants at pressure $p_{0}=1.013$ bar and temperature $T_{0}=25^{\circ} \mathrm{C}$;

An average heat source temperature has been taken as $30^{\circ} \mathrm{C}$, so the evaporating temperature is $20^{\circ} \mathrm{C}$ by assuming an average temperature difference of $10{ }^{\circ} \mathrm{C}$ in the evaporator. Internal heat exchanger effectiveness is taken as $60 \%$ for the analysis. Here, comparisons of some applications are presented for outlet temperatures of $60{ }^{\circ} \mathrm{C}$.

It is important to understand that, for $\mathrm{CO}_{2}$ to operate subcritically, the heat rejection temperature must be below the critical point, which is not high enough for water heating applications. Typically, water needs to be heated to at least $60{ }^{\circ} \mathrm{C}$ for domestic hot water applications. To achieve higher temperatures and a larger heating capacity, the system can be operated transcritically with the heat rejection pressure above the vapor dome.

Although these high pressures may pose safety risks during operation, and require robustly designed components with compatible material characteristics, the latest manufacturing technologies can easily meet the quality and safety standards required. A potential benefit of operating at high pressure is that the increased vapor density enables the use of smaller components and more compact systems [6].

In order to predict the optimum heat rejection pressure (discharge pressure) a correlation proposed by [4] was calculated:

$$
p_{\text {opt }}=4.9+2.25 t_{\text {cond }}-0.17 t_{\text {ev }}+0.002 t_{\text {cond }}^{2}=14.4 \mathrm{MPa}
$$

or

$$
p_{o p t}=\left(2.778-0.0157 t_{e v}\right) t_{c o n d}+\left(0.381 t_{e v}-9.34\right)=14.6 \mathrm{MPa}
$$

The heat pump system working on $\mathrm{CO}_{2}$ consists of evaporator, a single compressor, gaz cooler, internal heat exchanger (IHE) and expansion device (Fig.1).

The main difference between theoretical cycle and real cycle in the expansion stage. Here the expansion device of the theoretical cycle configuration is substituted by an expander or turbine (Fig. 1b). Furthermore, in the compressor adiabatic compression is replaced by polytrophic compression (nonisentropic process).

The $\log P$ - $h$ chart of one-stage carbon dioxide transcritical heat pump cycles are plotted in Fig. 2. 

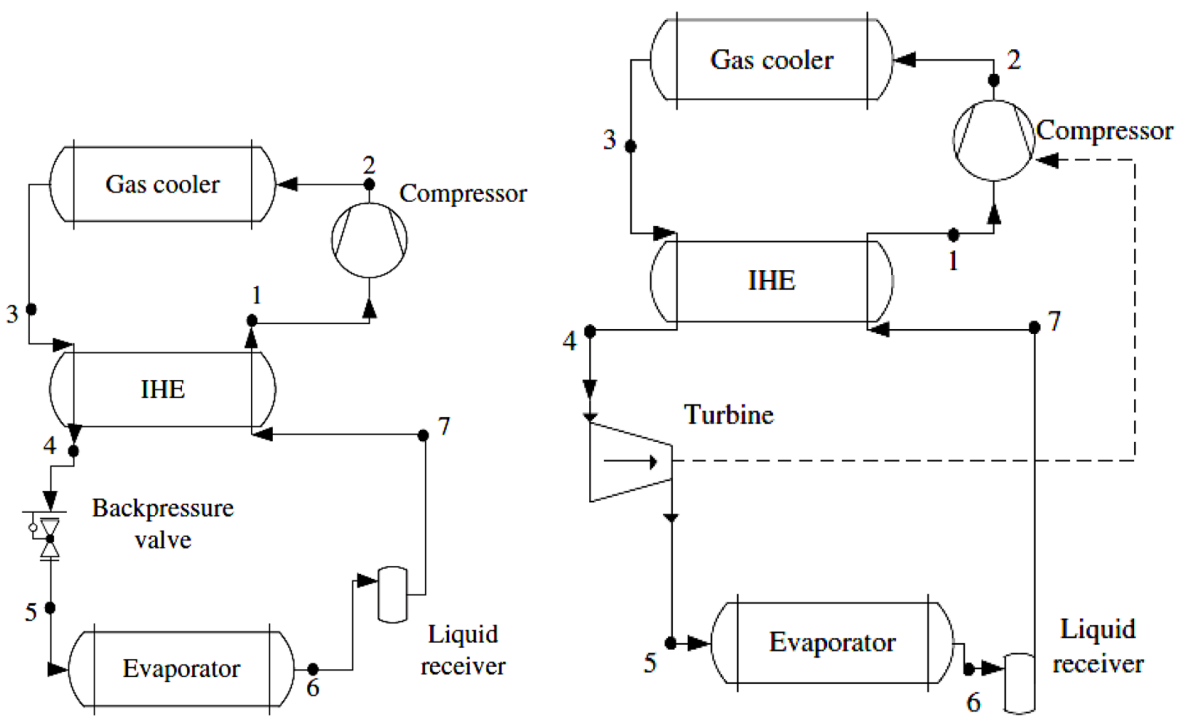

Fig. 1. Example for medium-temperature water-to-water vapor compression heat pump using R744

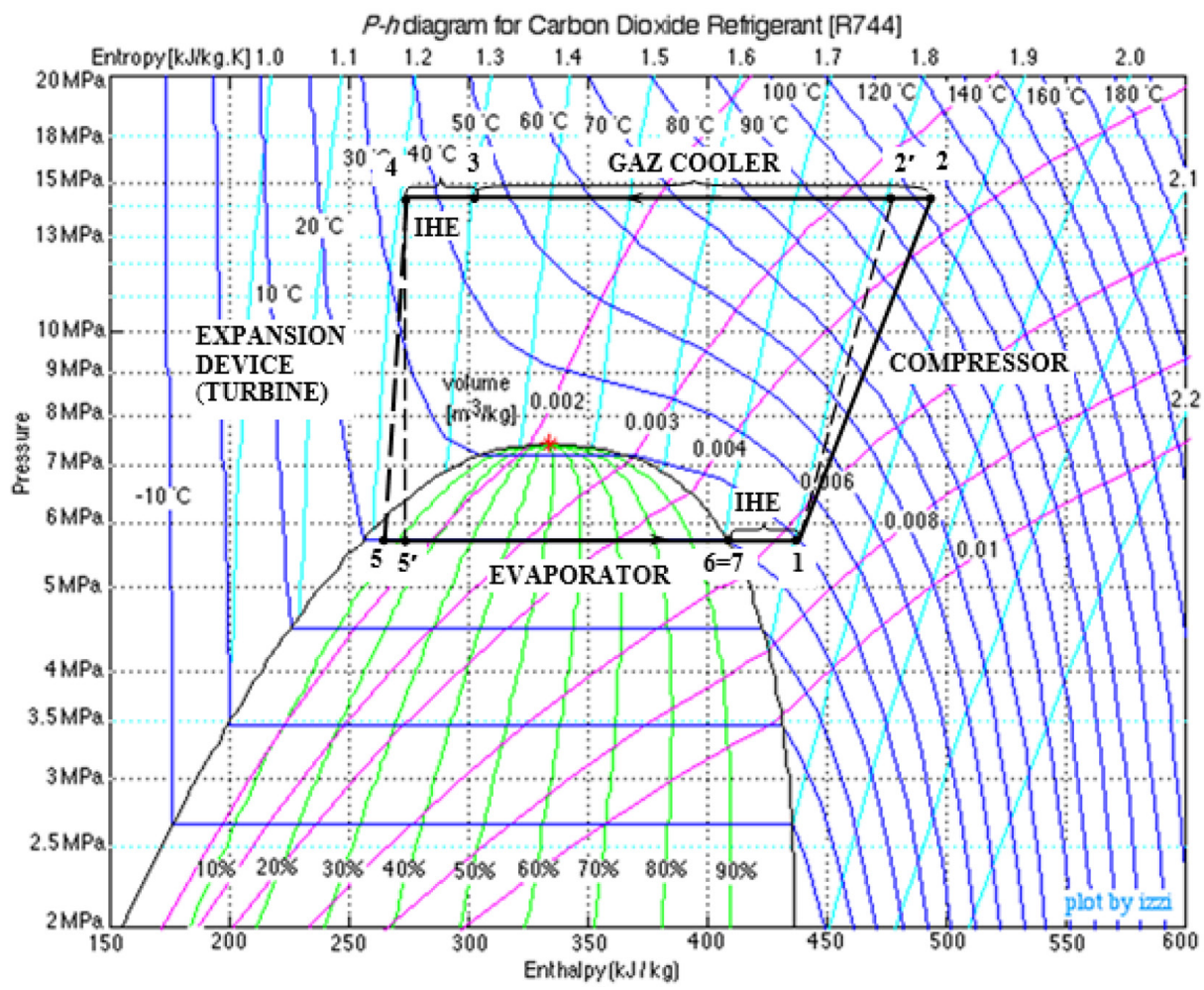

Fig. 2. Log p-h diagram of one-stage carbon dioxide transcritical heat pump cycles: $1-2$ '-3-4-5'-6-1- theoretical cycle; 1-2-3-4-5-6-1 real cycle 
It is known that the performance of a heat pump is defined by the coefficient of performance $\left(C O P_{h . p}\right)$ defined as the ratio of the heating capacity $Q_{h}$. to the power input $W_{\text {comp }}$ and indicated in equation (1):

$$
C O P_{h . p}=\frac{Q_{h .}}{W_{c o m p}}
$$

As mentioned in [7] for an ideal heat pump, operating between process and waste heat streams with constant heat capacities and varying temperatures (temperature glides), the maximum theoretical $\mathrm{COP}$ is known as the Lorenz COP and is given by equation (2):

$$
C O P_{\text {Lorenz }}=\frac{T_{L M . H}}{T_{L M . H}-T_{L M . L}},
$$

where $T_{L M(H, L)}=\frac{T_{\text {in }}-T_{\text {out }}}{\ln \left(\frac{T_{\text {in }}}{T_{\text {out }}}\right)}-$ the $\log$ mean temperature, $\mathrm{K}(H$ for high temperature side in the cycle;

$L$ for low temperature side in the cycle).

In practice, thermodynamic processes contain numerous losses which reduce the actual COP to a fraction of the Lorenz COP value. An efficiency term (known as a second law or exegetic efficiency), which relates the actual COP to the maximum Lorenz COP is given in Equation (3).

$$
\eta_{\text {ex }}=\eta_{\text {Lorenz }}=\frac{C O P_{\text {h.p. }}}{C O P_{\text {Lorenz }}}
$$

When choosing a new refrigerant for an application such parameters as affordability, safety and environment have to be considered simultaneously. Sustainability index $(S I)$ is given by equation (4).

$$
S I=\frac{1}{\left(1-\eta_{e x}\right)}
$$

Calculated data for both cycles are shown in Table 1.

Table 1. Calculated data for theoretical and real cycles

\begin{tabular}{|l|c|c|c|c|c|c|}
\hline \multicolumn{1}{|c|}{ Cycle } & $T_{L M . H}$ & $T_{L M . L}$ & COPLorenz & COPh.p & $\eta_{\text {Lorenz }}$ & SI \\
\hline Theoretical cycle & 323 & 305.46 & 18.47 & 3.83 & 0.21 & 1.26 \\
\hline Real cycle & 323 & 305.46 & 18.47 & 3.14 & 0.15 & 1.18 \\
\hline
\end{tabular}

Obtained values of $\mathrm{COP}_{\text {Lorenz }}, C O P_{h . p}, \eta_{\text {Lorenz }}$ have a good corresponding with other research in literature [8].

Applying an exergy balance and energy conservation to each component of the system, the following modular relations can be developed to yield the system model. 
Evaporator

$$
\begin{aligned}
& m_{r} e x_{i n}+m_{r} q_{\text {evap }}\left(1-\frac{T_{0}}{\bar{T}_{L P S}^{\text {evap }}}\right)=m_{r} e x_{\text {out }}-m_{r} e x_{\text {dest.evap }} . \\
& m_{r} e x_{\text {dest.evap }}=m_{r}\left(e x_{\text {out }}-e x_{i n}\right)-m_{r} q_{\text {evap }}\left(1-\frac{T_{0}}{\bar{T}_{L P S}^{\text {evap }}}\right)
\end{aligned}
$$

or using enthalpy and entropy of specific points from diagram equation can be rewritten as

$$
\begin{aligned}
& m_{r} e_{\text {dest.evap }}=m_{r}\left[\left(h_{1}-h_{5^{\prime}}\right)-T_{0}\left(s_{1}-s_{5^{\prime}}\right)\right]-m_{r} q_{\text {evap }}\left(1-\frac{T_{0}}{\bar{T}_{L P S}^{\text {evap }}}\right)= \\
& =e x_{\text {dest.evap }}=q_{\text {evap }}\left(1-\frac{T_{0}}{\bar{T}_{L P S}^{\text {evap }}}\right)-\left[\left(h_{5^{\prime}}-h_{1}\right)-T_{0}\left(s_{5^{\prime}}-s_{1}\right)\right],
\end{aligned}
$$

where $\left(1-\frac{T_{0}}{\bar{T}_{L P S}^{\text {evap }}}\right) \cdot q_{\text {evap }}=e x_{\text {evap }}-$ exergy had been released from low potential source $(L P S)$ in the evaporator; $\bar{T}_{L P S}^{\text {evap }}$ - average logarithmic temperature of the $L P S, \mathrm{~K}$.

$$
\bar{T}_{L P S}^{\text {evap }}=\frac{t_{\text {low1 }}-t_{\text {low } 2}}{\ln \frac{t_{\text {low1 }}+273}{t_{\text {low } 2}+273}} .
$$

\section{Compressor}

External exergy losses (destruction) in the compressor and electric motor caused by mechanical friction

$$
e x_{\text {dest.comp }}^{\text {ext }}=W_{\text {comp }}-l_{\text {comp }}
$$

Internal exergy losses in the compressor caused by the irreversibility of the compression process:

$$
\text { ex } \operatorname{exst.comp~}_{\text {int }}=T_{0}\left(s_{2^{\prime}}-s_{1}\right) \text {. }
$$

Condenser

$$
\begin{aligned}
& m_{r} e x_{\text {in }}=m_{r} e x_{\text {out }}+m_{r} q_{\text {cond }}\left(1-\frac{T_{0}}{\bar{T}_{H P S}^{\text {cond }}}\right)+m_{r} e x_{\text {dest.cond }} . \\
& m_{r} e x_{\text {dest.cond }}=m_{r}\left(e x_{i n}-e x_{\text {out }}\right)-m_{r} q_{\text {cond }}\left(1-\frac{T_{0}}{\bar{T}_{H P S}^{\text {cond }}}\right) \text { or } \\
& e x_{\text {dest.cond }}=\left(h_{2^{\prime}}-h_{3}-T_{0}\left(s_{2^{\prime}}-s_{3}\right)\right)-q_{\text {cond }}\left(1-\frac{T_{0}}{\bar{T}_{H P S}^{\text {cond }}}\right) \\
& =\left(q_{\text {cond }}-T_{0}\left(s_{2^{\prime}}-s_{3}\right)\right)-q_{\text {cond }}\left(1-\frac{T_{0}}{\bar{T}_{H P S}^{\text {cond }}}\right) \\
& e x_{\text {dest.cond }}=\left(q_{\text {cond }}-T_{0}\left(s_{2^{\prime}}-s_{3}\right)\right)-q_{\text {cond }}\left(1-\frac{T_{0}}{\bar{T}_{H P S}^{c o n d}}\right) .
\end{aligned}
$$


where $q_{\text {cond }}\left(1-\frac{T_{0}}{\bar{T}_{H P S}^{\text {cond }}}\right)=e x_{\text {cond }}$ high potential source's (HPS) exergy had been taken in the condenser; $\bar{T}_{H P S}^{c o n d}$ - average logarithmic temperature of the HPS, K.

$$
\bar{T}_{H P S}^{c o n d}=\frac{t_{\text {high } 2}-t_{\text {high } 1}}{\ln \frac{t_{\text {high } 2}+273}{t_{\text {high } 1}+273}}
$$

Internal heat exchanger (IHE)

$$
m_{r} e x_{\text {dest.LVHE }}=m_{r} T_{0}\left(s_{1}-s_{6}-\left(s_{3}-s_{4}\right)\right)=m_{r} T_{0}\left(s_{1}-s_{6}-s_{3}+s_{4}\right) .
$$

Expansion device

$$
\begin{aligned}
& m_{r} e x_{i n}=m_{r} e x_{o u t}+m_{r} e x_{\text {dest.thr } v} . \\
& e x_{\text {dest.thr } v}=m_{r}\left(e x_{\text {in }}-e x_{\text {out }}\right)=m_{r} T_{0}\left(s_{5^{\prime}}-s_{4}\right)
\end{aligned}
$$

Total exergy destruction can be calculated as the sum of exergy destruction in different components of the system.

$$
\begin{aligned}
& e x_{\text {dest }}^{\text {total }}=e x_{\text {dest.evap }}+e x_{\text {dest.comp }}^{e x t}+e x_{\text {dest.comp }}^{\text {int }}+e x_{\text {dest.s.c. }}+e x_{\text {dest.LVHE }}+e x_{\text {dest.thr } v} . \\
& \eta_{e x}=\frac{e x_{\text {out }}}{e x_{\text {in }}}=\frac{e x_{\text {cond }}+e x_{\text {s.c. }}}{e x_{\text {evap }}+e x_{\text {comp }}^{e x t}}=1-\frac{e x_{\text {dest }}}{e x_{\text {in }}}
\end{aligned}
$$

For real cycle parameters for points 2 and 5 have been used instead of $2^{\prime}$ and 5 ', respectively.

This analysis takes into account all the losses appearing in the heat pump system, for calculating exergetic efficiency. The various parameters calculated are COP, exergetic efficiency, exergy destruction and efficiency defects.

All calculations and diagrams were carried out with the help of freeware CoolPack («CoolPack IPU,» n. d.) ver. 1.46, freeware REFPROF ver.9 (NIST Standart Reference Datebase 23) and Microsoft Excel 2010.

The exergy loss in the different components is shown in Fig. 3.

Process irreversibility (due to mixing, throttling, internal convection, etc.), pressure loss due to friction in inlet and outlet valves and heat loss to the environment are the basic reasons for the exergy loss in the compressor. The summarized exergy loss for real cycle is maximum in the compressor $\left(e x_{\text {comp }}=e x_{\text {comp.inter. }}+e x_{\text {comp.exter. }}=46 \%\right)$, while the summarized exergy loss for theoretical cycle is less $\left(e x_{\text {comp }}=e x_{\text {comp.exter }}=19 \%\right)$, because the internal exergy loss equals zero.

The maximum increment of irreversibility for both cycles occurred in the gas cooler (condenser) (30\% and $27 \%$ ). This may be attributed to an increase in the temperature difference in the gas cooler as well as the increase in pressure loss due to the rapid increase in flow velocity. So, an increase in compressor speed yields higher capacity due to the higher mass flow rate and higher frictional pressure loss due to the higher velocity that causes the increase in irreversibility as well.

As was mentioned in [9], irreversibilities in the evaporator and the gas cooler occur due to the temperature differences existing between the two heat exchanger fluids, pressure loss, flow imbalance 

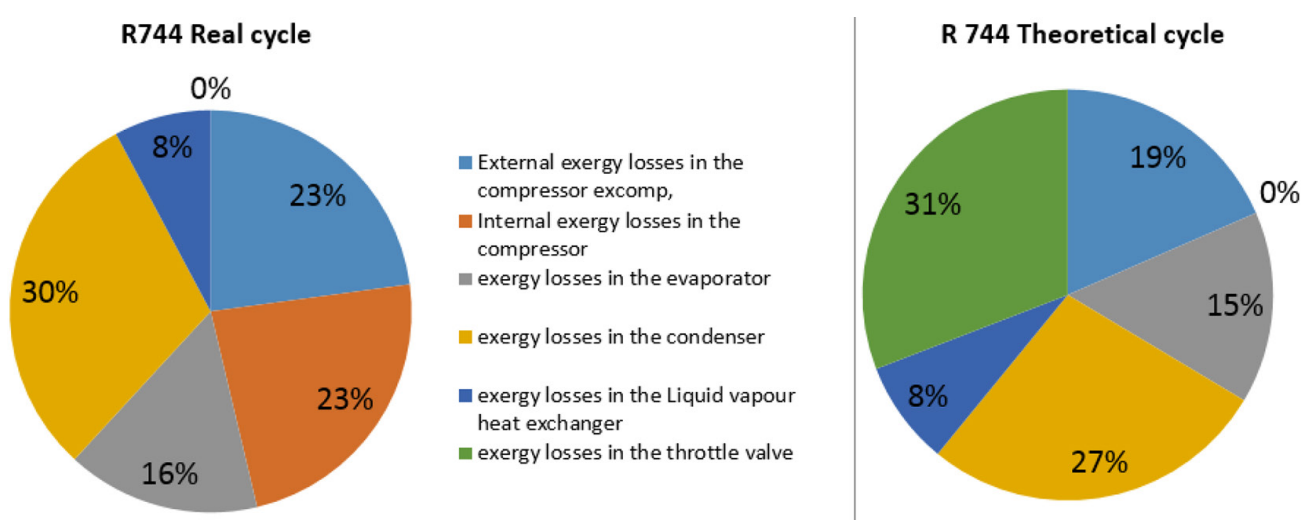

Fig. 3. The exergy loss in the different components of heat pump

and heat transfer with the ambient. The results show that almost $90 \%$ of the irreversibility occurs due to the fluid temperature difference and $10 \%$ due to the rest.

At the mean conditions, the average fluid temperature differences in the evaporator and gas cooler are about 22 and $49{ }^{\circ} \mathrm{C}$, respectively. It is observed that the exergy losses in evaporator and in IHE for both cycles are similar, $16 \%$ and $8 \%$, respectively.

Replacement of the expansion valve by a turbine is the only option available to improve the performance of the system and reduce the irreversibility of the expansion process. It was reported that an expansion work recovery turbine with isentropic efficiency of $60 \%$ would reduce the contribution of this process to total cycle irreversibility by $31 \%$ in the thermodynamic cycle. Hence, improvement in system performance through this technique is quite significant. However, such extensive hardware addition may not be economically feasible in many practical applications, especially for small capacities.

Schematic layout of food industry enterprises recycled water supply system with parallel functioning water-cooling tower and medium-temperature water-to-water vapor compression heat pump using R744 is shown in Fig.4.

The flow of water from the heat exchanger (1) is directed partly for cooling to the water cooling tower (7) and to the heat pump (4). The thermal potential of water (the so-called low-grade heat) is passed to the working substance of the heat pump and then is transferred to the water which comes from the consumer (high-potential source). Water flow is regulated by valves (3). Amount of water coming from the heat exchanger (1) usually is significant, and it is not advisable to chill all water in the heat pump, because the consumer does not need so such hot water. 


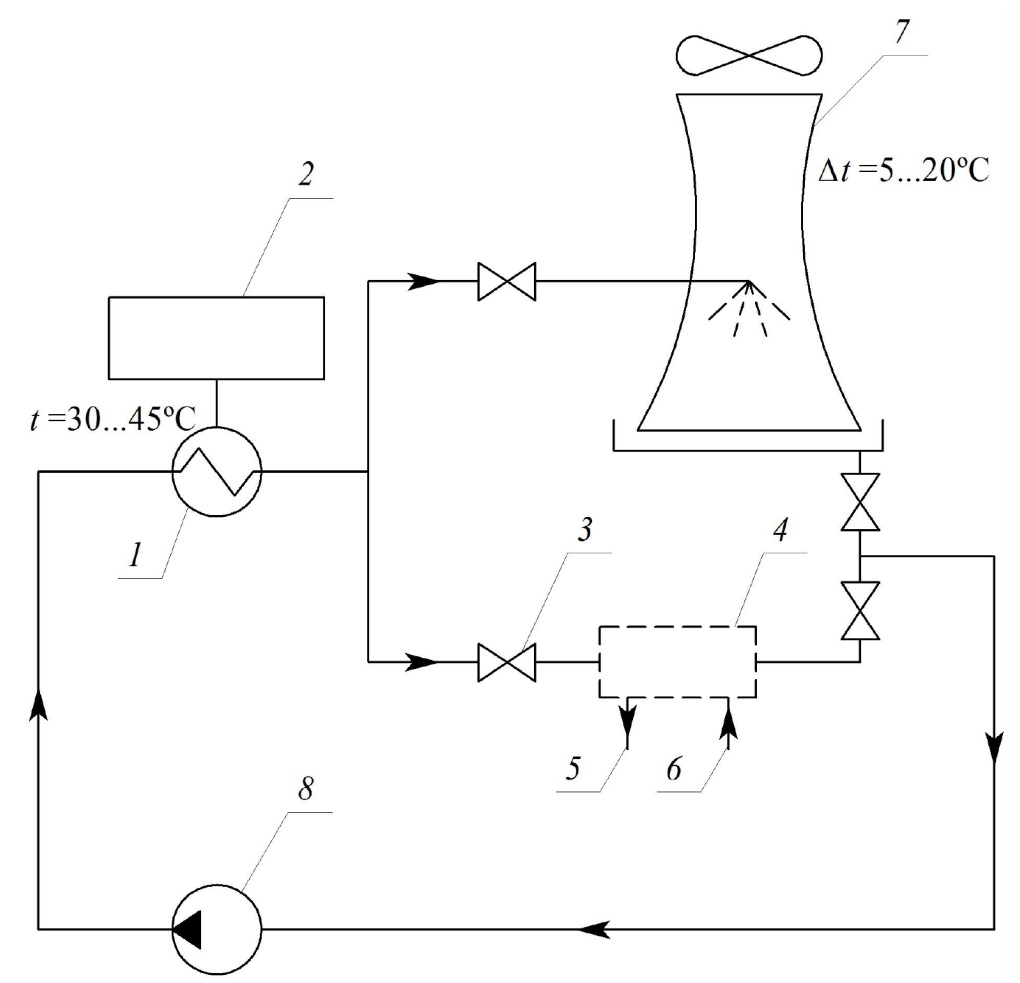

Fig. 4. Layout of food industry enterprises recycled water supply system with parallel functioning water-cooling tower and medium-temperature water-to-water vapor compression heat pump using R744: 1 heat exchanger of technology equipment; 2 technology equipment; 3 control valve; 4 medium-temperature water-to-water vapor compression heat pump; 5 supply hot water line to the consume; 6 supply water line from the consume; 7 watercooling tower; 8 circulation pump

\section{Conclusion}

Recycled water $\left(t_{w}=25 \ldots 40^{\circ} \mathrm{C}\right)$ of food production enterprises has a strong potential to be a source of low potential heat for $\mathrm{CO}_{2}$ medium-temperature water-to-water vapor compression heat pump for heating processes.

The exergy flow diagram shows that all the components except the internal heat exchanger contribute significantly to the irreversibilities of the system.

Experimental results for the heating performance of the $\mathrm{CO}_{2}$ trans-critical theoretical cycle show that the values of COP and second law efficiency are 3.83 and $21 \%$, for real cycle 3.14 and $15 \%$, respectively.

\section{References}

[1] Klemeš J. J., Varbanov P. S., Lam H.L. Water footprint, water recycling and food-industry supply chains. Handbook of waste management and co-product recovery, 2009, 134-168, DO I:10.1533/9781845697051.2.134. [Electronic resourse] Access: https://www.researchgate.net/ publication/288763712_Water_footprint_water_recycling_and_food-industry_supply_chains.

[2] Aniko N. Toth. The Geothermal Potential of CO2 Based Heat Pumps Used in an Abandoned Coal Mine. Proceedings, Fourtieth Workshop on Geothermal Reservoir Engineering Stanford 
University, Stanford, California, January 26-28, 2015. [Electronic resourse] Access: https://www. researchgate.net/publication/272743064.

[3] Baomin Daia, Pu Zhao, Shengchun Liu, Mingqiang Su, Dan Zhongb,, Jiabao Qiana, Xiaowei Hu, Ying Hao. Assessment of heat pump with carbon dioxide/low-global warming potential working fluid mixture for drying process: Energy and emissions saving potential. Int.J. Energy Conversion and Management 222, 2020, 113225, 1-17.

[4] Sarkar J., Bhattacharyya S., Gopal M. Ram. Transcritical Carbon Dioxide Based Heat Pumps: Process Heat Applications. International Refrigeration and Air Conditioning Conference, 2004. Paper 691. [Electronic resourse] Access: https://docs.lib.purdue.edu/cgi/viewcontent. cgi?article $=1690 \&$ context $=$ iracc.

[5] Alptug Yataganbaba, Ali Kilicarslan, I' rfan Kurtbas. Exergy analysis of R1234yf and R1234ze as R134a replacements in a two evaporator vapour compression refrigeration system. Int. J. of refrigeration, 2015, 60, 26-37. DOI: 10.1016/j.ijrefrig.2015.08.010 [Electronic resourse] Access: https://www.researchgate.net/publication/283835765_Exergy_analysis_of_R1234yf_and_R1234ze_ as_R134a_replacements_in_a_two_evaporator_vapour_compression_refrigeration_system).

[6] Kashif Nawaz, Bo Shen, Ahmed Elatar, Van Baxter, Omar Abdelaziz, Performance optimization of $\mathrm{CO}_{2}$ heat pump water heater. International Journal of Refrigeration, 2017, https://doi.org/doi:10.1016/j.ijrefrig.2017.09.027. [Electronic resourse] Access: https://www. researchgate.net/publication/320406720_Performance_optimization_of_CO_2_heat_pump_water_ heater.

[7] Spoelstra M. S., Zondag H. A., Wemmers A.K. An estimation of the European industrial heat pump market potential. Int. J. Renewable and Sustainable Energy Reviews, 2021, 139, [Electronic resourse] Access: https://www.researchgate.net/publication/348684396_An_estimation_of_the_ European_industrial_heat_pump_market_potential).

[8] Shuai Deng, Ruzhu Wang, and Yanjun Dai. A comparative analysis on experimental performance of $\mathrm{CO} 2$ trans-critical cycle. Int. J. HVAC\&R Research, 2014, 20, 1-13. DOI: 10.1080/10789669.2014.913959.

[9] J. Sarkar, Souvik Bhattacharyya, M. Ram Gopal. Transcritical CO2 heat pump systems: exergy analysis including heat transfer and fluid flow effects. Int. J. Energy Conversion and Management, 2005, 46, 2053-2067. doi:10.1016/j.enconman.2004.10.022 [Electronic resourse] Access: https://www. researchgate.net/publication/223491227_Transcritical_CO $\mathrm{CO}_{2}$ heat_pump_systems_Exergy_analysis_ including_heat_transfer_and_fluid_flow_effects). 